\title{
EXPLORING STRATEGIES FOR EFFECTIVE EXPERIENCES FOR EDUCATION AND INDUSTRY
}

Dr Lesley Gill

\section{INTRODUCTION}

In 2019, a learning collaboration document between the DHB and Otago Polytechnic was signed, with the aim of enriching the educational and employment experiences of 25 second-year HRM students studying at Otago Polytechnic in the School of Business, and for strengthening the DHB's staff induction experience. The focus of the shared learning experience was full participation in the actual induction training programme undertaken at the Southern DHB Dunedin as well as completing an eighthour elearning supplom prary comp undent An ind the

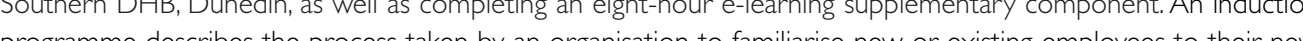
program do res

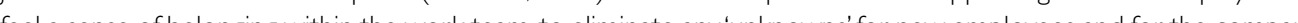
feel a sense or belonging within the work team to

The purpose of employee induction programmes is to integrate employees from outside the organisation into the organisation, and so become inducted and acclimatised to their new work environment (Stone, 2013). Through the portrayal of organisational culture from organisational trainers, the sense of organisational identity is enhanced The advantage of employee induction training is to help new employees adapt to the company environment as soon as possible and enter the job role feeling equipped. In the DHB induction training programme, members of the leadership team introduced themselves and articulated the vision and mission of the organisations as well as explaining their role in the organisation, and offered to help with issues involving the new work place. This way induction training can reduce the anxiety of new employees (Boxall \& Purcell, 2016).

This article presents student perspectives as themed from the data analysis. Findings from the interview are presented along with their recommendations. Conclusions draw it all together and offer direction for future research.

\section{LITERATURE REVIEW}

The literature encompasses the benefits of collaborative undertakings, strengths-based learning, on- and offjob training choices, the power of multiple learning platforms such as coaching, and the purpose of induction programmes, including addressing health, safety and wellbeing accountabilities.

\section{Cultivating inter-organisational collaborations}

While industry-educational collaborations are not new, the nature of that collaboration has certainly changed over time (Cerych, 1989). Tener (1996) notes the degree to which construction engineering graduates are prepared to perform well in practice is further enhanced by effective industry-university cooperation on such matters as the

construction education mission and objectives, curriculum, course content, faculty qualifications and development, resources, co-ops and internships, and other issues. Collaborative strategies have come to include more than knowledge sharing; rather, learning collaborations have taken on significantly more of an experiential application; a hands on grounded approach vis-à-vis traditional teacher-directed training models. Tertiary-industry collaborations provide "insights into corporate issues at an applied practical level" (Beckman, Coulter, Khajenoori, \& Mead, 1997. p. 50).

One of the reasons why industry engages with educators is that there is a shared learning philosophy that ensures "equity, inclusion, social mobility, and lifelong learning" (Rusten \& Hermelin, 2017. p. 813). It is also an excellent way to build relationships and networks with potential candidates for future recruitment and "efficient strategies to secure a highly qualified and motivated labour force" (Rusten \& Hermelin, 2017, p. 823). Trust is a key element of successful collaborations (Leino, 2017). Trust is defined as "the expectation that others can be relied upon, demonstrated through one's readiness to talk about issues with which one experiences feelings of vulnerability" (Gill \& Ramsey 2012, p. 125).

This joint collaboration strengthens industry-educational networks and relationships, and HR processes, creating win-win for both organisations. This learning collaboration offered students a lived experience of real industry HR processes. It also created a platform for generating feedback on the current induction programme that employees experience when joining the DHB, thus providing authentic insights for the DHB. Additionally inviting 'visitors' (students) to the induction process gave DHB trainers a fresh perspective of their training programme and increased self-awareness of content and delivery relevance and compliance, as well as giving attending staff a sharpened perspective of their training course. Furthermore, it identified potential HR workers for the future to DHB management and HR staff.

\section{From strength to strength}

Historically, teachers tended to address deficits, which "can communicate a sense of failure and helplessness, reinforce low expectations, create dependency on outside resources and agency-created solutions, and discourage individuals from moving in the direction of positive outcomes" (O'Connell, 2006, p. I). Strength-based learning emphasises deliberate capability development and solution-oriented thinking (Staron, Jasinki, \& Weatherley, 2006) and typically is used in restorative justice, children and families; employment; youth, and counselling with the focus of this paper on its application to teaching Contemporary research indicates learners are responsive to strengthbased learning approaches that focus on the positives, strengths and adequacies (Anderson 2005. Buckingth 2007: O'Connell, 2006: Waterhouse \& Virsona 2008). An emphasis on achievement automatically improves areas of : Fischer 2006) Henry and Henry (1999) conty with a conscious fear of falle (Buckngham \& Claton, 2001

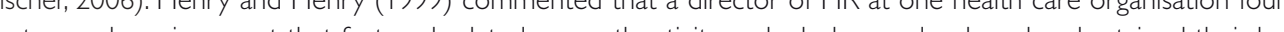
employees

Buckingham and Clifton (200I) noted that 80 per cent of successful managers spend their time on employees' strengths rather than their limitations, underscoring the importance of bulding on employee strength . Rath (2007, as a excellent quality-of-life in general".

\section{On- and off-job training options}

Students commented on the advantages and disadvantages of on- and off-job training. Through training, employees can learn professional knowledge and apply it to their work, so that they can better contribute to organisational 列 for the organisation. In-house training usually relates to a specific job, for example, how to use certain machinery 
or software, and offered by employees with the specific critical expertise. An advantage of in-house training is that it keeps costs down and is flexible enough to meet the needs of the organisation. On the other hand, if outside experts with new ideas and up to date methods are not consulted the organisation may be at a disadvantage in the future (Johnson, Whittington, \& Scholes, 201 I)

On-the-job coaching is defined as a way to facilitate employee skills training and can be met from within the Pozo, 2012). Overall, coaching can foster a more intimate and quicker learning experience for new employees consequently increasing organisational production and efficiency. The disadvantages of this training surround the also simutaner' capacty to com muncate or provide guidance. If the training is happening while both parties are also simulaneously working for example, then the coach or trainer can become distracted and, in this situation. frustrate the new employce resuling in a loss of retention (Vidas this research was on the job taining a lough or some enployes came together from other ph DHB. This strategy proved useful as it kept the focus on the environment in which the induction training related.

\section{Cultivating team coaching or mentoring:A win-win collaborative learning platform}

Team coaching is a powerful training process that promotes the success of teams and organisations. Active team coaching is consistent with a strength-based approach. The foundation of active team coaching has evolved from recognising the complexity of working within teams and building the additional skills and abilities needed to succeed, by focussing on individual expertise that individuals input cumulatively. Active team coaching encourages creativity builds mutual respect and value, strengthens the team, and accelerates learning (Brennan \& Hellbom, 2016). A strength-based approach focuses on the positive aspects of behaviours, as framing training negatively in an employee induction can lead to subconscious negative feelings resulting in employees having a lack of confidence. Removing negatively framed statements will improve employee retention job satisfaction and make the new employees feel more comfortable in their new working environment (Hiemstra \& Van Yperen, 2015).

Similarly, mentoring occurs after an employee has completed induction and in-house training. Mentoring is a method of on-job training tailored to make an employee feel welcomed, as well as, confident while being guide through onthe-job challenges by a colleague with considerable experience (Gibb, 1994). To be effective, mentoring should be together in developing the skills of the new employee.

\section{METHOD}

Case study methodology underpinned this research. A case study is an extensive examination of a single instance of a phenomenon of interest and gives opportunity to use data that are both descriptive and explanatory (Dey 1996). The importance of the context (environmental factors - actual and dynamic) is essential. Case studies provide an opportunity for students to "enjoy an active learning experience and derive the experiential payback tha such activities offer" (Vega, 2009, p. 574). A case study approach allows for inquiry into the complexities of divers contexts and processes around a central focus (Dey, 1996).

The study used two research methods: documentation - thematic exploration, and interview. Student assessments based on their experience of the DHB's induction process, were used as a basis of data analysis from a reflective and substantive perspective. An independent marker ensured that there was no conflict of interest and/or breach of ethics. Student work was anonymised before data analysis occurred. The Otago Polytechnic Ethics committee approved this research.
The director of organisational learning at the DHB was interviewed to gain her perspective of the learning collaboration to discover (I) What worked? (2) What did not work? (3) How has looking through others' lens influenced current induction practice? (4) What they might do differently in the future (5) Reflections on learner involvement in their induction process (6) Take home new learnings/ideas/innovations for future induction (7) Advantages and disadvantages of the learning collaboration, and; (8) Something else?

Students attended the induction programme on 19 March 2019 and then used this learning experience to write an assessment (formative and summative report) that met the HR course learning objectives. The student experience integrated e-learning from the DHB training, which meant students reported on their experience of an actual induction programme in a real organisation. The learning collaboration created an opportunity for students to reflect on their growing knowledge and experience of HR. The design of their assessment offered a format to identify the strengths and weaknesses of this induction process at the DHB, and an opportunity to integrate HR theory explicitly into actual HR practice which in turn created a-ha moments for students. The training experience generated a direct link between 'learning' and workplace practice, making the learning 'real' while also helping students meet and network with employers.

In small groups, students also reported their findings back via a presentation to DHB management. The student reflections and recommendations generated from five student groups were analysed for insights and themes. Reflection is "the practice of periodically stepping back to ponder the meaning to self and to others in one's immediate environment about what has recently transpired" (Cano \& Lidon, 201 I, p. 525).

\section{DATAANALYSIS}

The opportunity to participate in a real-time live induction process was not lost on the students, in that the staff were valued. Many students also stated how much they felt valued as captured in these comments

After attending the induction programme - it made us feel honoured to have the opportunity to be a part of a formal induction

The way the DHB treated us during the time of the meeting was very welcoming, kind and considerate which made us feel like we were being inducted into their organisation, which gave us all a sense of selfworth.

When they asked us to introduce ourselves, I noticed that they were listening attentively, and you could tell when they found something interesting about one of us because of their expressions and reactions were uplifting.

The DHB's induction programme made us feel privileged as we experienced first-hand what an induction programme is, how it works and what happens. The experience also allowed us to gain access to an E-learning platform that again, we thought was a privilege as we had further information provided to us. We saw this as a fantastic opportunity to gain knowledge for not only our assessment but knowledge for everyday life. The induction programme also made us feel as if we were a part of the team at SDHB, through their continuous use and portrayal of their core values.

A variety of strengths of the DHB's induction programme that students highlighted are:

Their core values of: Kind; Open; Positive and; Community, described how they expect everyone who works within the DHB to involve these values when working with patients, whanau, colleagues, providers and other organisations, and applied to existing and new employees. 
The induction programme presenters did a fantastic job. They engaged with the audience and created an enthusiastic atmosphere, which made the programme a lot more enjoyable.

We were impressed with the Maori welcoming, this showed us that Maori culture is important within DHB and showed us the appreciation they have towards Maori working with DHB and those who will.

As individuals [students] the induction programme taught us new knowledge and reminded us of existing knowledge that has changed the way we view HRM and the way we view ourselves as a person. One thing we all took away as a team was that there is a lot more to managing a hospital than we all thought from the use of security to emergency management that work together to create a safe environment for families, patients and employees. As an HR practitioner, we have gained valuable understanding of what is

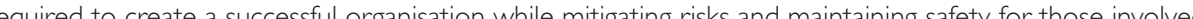
directly and indirectly of an organisation.

t was quite surprising to hear how many staff members could speak fluent Te Reo.

One of the most important things in a medical workplace is to understand the environment in which the employee will work to ensure the safety of yourself and others (Pollock, 2015). For instance, in the DHB induction, new employees learnt what to do in case of an emergency and training that increased their awareness of health and safety situations. One member of the induction team conducted a presentation about emergency management and specific fire extinguisher use, as well as customer behaviour management, thereby introducing new employees to hazards particular to a hospital setting

\section{INDUCTION PROGRAMME ANALYSIS}

The benefits of running induction programmes before this collaboration was mostly only theoretical for many of the students. Students overwhelmingly commented on how much they appreciated the experience and how much they learned from it. This tangible experience reinforced theory in practice for them. One group said

Before we took part in this induction activity, we did not realise the importance of induction programmes. On reflection, we now believe it plays a very important role. New employees may have doubts about whether they can adapt to the new working environment and job requirements, what their personal development space is and whether they can integrate into the new corporate culture Induction training can help employes reduce their psychological discomfort and move them into the job role as soon as possible. One of the strengths of this programme was the mihi; many of us students felt it was a great way to connect with each other. It set the environment making everyone feel closer and more comfortable. Having the flax activity was also another great interaction: this was one of our favourite parts. It allowed for engagement in the induction process and it seemed to make everyone feel more relaxed and rather than just to participate in a formal occasion.

\section{STUDENT INSIGHTS}

Recommendations proposed by students offer the DHB and anyone involved in staff induction and training, fresh insights for undertaking effective induction programmes. This section formed part of their assessment, and does not take away from the exceptional induction programme they experienced.

Firstly, one component of the induction that would enrich the Violence Intervention programme focuses on the impact of the training on the employees personally. The trainer spoke about many issues that could have potentially triggered events for new employees. There was no disclaimer offered be the trainer who started speaking about a offer support if they become over short cases studies to strengthen the learning.

Students recommended having this event in a larger room, which may help create more of a flow so people could have a little bit more space and room to get out and go to the bathroom or to get a glass of water Perhaps there could be a short interval towards the end quarter of the induction programme The addition of 25 more people (the students) contributed to the issue.

Students noticed that a few speakers were going overtime, and did not show consideration to speakers presenting after them by adjusting their own presentations or ensuring they finished on time. This lack of care and concern for others' presentations might point to not living up to their organisational values. Having a short break could also help maintain everyone's attention and concentration.

Nevertheless, students said it was a very informative experience; the speakers were very knowledgeable and communicative which meant there were not many questions asked. The lack of questions might also point to the framing of the invitation, the pressure on time, or the confidence of the employees to speak up in a mixed-group/ disciplines setting.

As a future HR practitioner I found it fascinating listening to this induction, I would have been intrigued to learn more about the specific areas of the workplace that they decided to include in the programme.

Overall having the opportunity to attend this induction was a very valuable experience. It gave us the chance to learn a lot more about the DHB and what it aims to achieve in the future, such as: faster treatment for cancer patients, shorter stays in the emergency department and increased immunisation. We had a very enjoyable time and feel more educated after attending this programme at the hospital and online.

We had a delightful experience at the DHB. We gained a lot of knowledge not only in human resource management but also about the Hospital's induction training programme.

\section{INTERVIEW FINDINGS}

This section summarises the DHB perspectives of this learning collaboration, and follows the questions posed to the interviewee.

\section{What worked?}

Having people other than DHB staff in the training provided new insights of the induction process, uncluttered by the cultural norms of those typically involved in the health sector 
It provided fresh eyes from a learning perspective; people who were there to analyse, not participate (formally).

The presentations were an excellent way of seeing through their [the students'] eyes.

\section{What did not work?}

The room. However, it was the biggest training room in the DHB, and adding the students amplified the 'problem'

\section{How has looking through others' lens influenced current induction practice?}

Comments included not having 'information overload' or too much sit-down PowerPoint presentations and ensuring there were adequate breaks.

\section{What might you do differently in the future?}

Comments included changing the room set up, check the content such as seeing what values we want to see and what behaviours we do not want to see. Increasing training around 'security' was also an area identified for development.

\section{Reflections on learner involvement in your induction process}

The impact of the training with students involved with staff was very positive. DHB managers were very welcoming and relaxed. When asked if they would be willing to do it again, there was a resounding "yes". Follow-up with staff would be useful to gain their perspectives of the joint training event. The possibility for developing modules from the induction process, for example, having other modules on demand i.e., which could be used in relation to Performance Appraisal, Performance Management. A couple of the presenters have already reviewed ther presentations. The experience also put "everyone 'on notice' to use best practice". Another insight was that the programme could be more interactive.

\section{Advantages and disadvantages of the learning collaboration}

The interviewee said there were no disadvantages. One of the main advantages was to have an opportunity to "learn from each other". Secondly, it was a way of "giving back; paying it forward". The interviewee is an alumnus of Otago Polytechnic's Bachelor of Applied Management degree (School of Business). She also commented on the advantages for students getting the "practical and essential corporate training experience" as they enter their third-year of HR study

\section{BRINGING IT ALL TOGETHER}

Students overwhelming supported this hands-on experience. Here are some of their final comments

Overall, we felt that the staff made us feel very valued and of an equal status rather than making it feel hierarchical. As attendees of this induction training, we felt honoured to be invited and to have been able to the team members were with each other This induction gave us an insight and more in-depth look into the background and behind scenes of what work goes on at the Wakari Hospital such as; security procedures, kaupapa Maori, emergency management.
As a staff member, I would have been very excited moving into a position here. The induction programme would have made me feel knowledgeable and respected. Hearing the values of the Hospital such as Manaakitanga (kind). Pono (open). Whai Whakaaro (positive) and Whanaungatanga (community) showed how they value everyone and support each other. It would have made me feel very safe moving into such progressive and caring workplace.

From the DHB's perspective, the collaboration was also successful, and provided an excellent platform for generating new insights and ideas for strengthening the current induction training programme. Implementing strategies that increase hands-on experiential learning in the field of HR prepares students for the complex real world of HR practice.

In conclusion, this paper presents an overview of an innovative way of collaborating with industry for developing and applying new knowledge and skills for all stakeholders, and demonstrates how changes to more traditional forms of education can achieve significant positive outcomes with minimal systems change.

Dr Lesley Gill. Lesley is a Principal Lecturer at Otago Polytechnic, teaching Leadership, Human resource management and Strategic Management. Her PhD focused on Emotional Intelligence training design. Lesley runs workshops in resilience, self-awareness, and empathy. She has hosted four El symposiums since 20I2. Lesley publishes her research in quality international and national peer-reviewed journals publications and conferences, and co-authored Organisations \& Management textbook.

\section{REFERENCES}

Anderson, E. (2005). Strengths-based educating: A concrete way to bring out the best in students - and yourself. Educational Horizons. 83(8), 180-189,

Beckman, K., Coulter, N., Khajenoori, S., \& Mead, N. R. (1997). Collaborations: Closing the industry-academia gap. IEEE Soffware. 14(6), 49-57.

Boxall, P., \& Purcell,.. (2016). Strategy and human resource management (4 ed.). London: Plagrave. Brennan, D. \& Hellbom, K. (2016). Positive team coaching. Industrial and Commercial Training. 48(7), 333-337.

Buckingham, M. (2007, September). Strength-based learning. Paper presented at the Global Leadership Summit., World-wide linked Video conference.

Buckingham, M., \& Clifton, D. (2001). Now discover your strengths. New York:The Free Press.

Cano, I. L., \& Lidon, I. (20I I ). Guided reflection on project definition. International Journal of Project Management. 29(5), 525-536. Cerych, L. (1989). University-Industry Collaboration: A Research Agenda and Some General Impacts on the Development of Higher Education European Journal of Education. 24(3), 309-313.

Dey, I. (1996). Qualitative Data Analysis: A User-friendly guide for social scientist. London: Routlage.

Fischer, M. (2006). Best practices guide for Generation X recruits and the field training experience. http://wnw.theiacp.org/Portals/o/ pdfs/Publications/BP-GenXRecruits.pdf

Gill, L.J. \& Ramsey. P. L. (2012). Shedding light on trust. Asia Pacific Management and Business Application. I (2), 117 -128. Henry, L., \& Henry,J. (1999). Reclaiming soul in health care. Chicargo: AHA Press

Hiemstra, D., \& Van Yperen, N. W. (2015). The effects of strength-based versus deficit-based self-regulated learning strategies on

Johnson. Whittington. R. \& Scholes K (2011) Exploring strategy Pearson Education: Rotolito Lombarda, Italy 
Leino, M. (20 17). Developing of a Quadruple Model for Collaborative Research Actions between Higher Education Institutions and Industry. (Doctoral). Retrieved from https://tutcris.tut.fi/portal/files/ I 085 I64/leino_I 477.pdf

O'Connell, D. (2006). Brief literature review on strength-based teaching and counselling. Retrieved from Toronto: mww.metrac.org/ resources/downloads/strength.based.learning.lit.review.pdf

Pollock, P.W. (2015). Learning to be engaged: Leader goal orientation, employee goal orientation and the mediating role of employee learning on employee engagement and performance (Order No. 3664489). Available from ProQuest Central. (1734885343). Retrieved from https://search.proquest.com/docview/I 734885343 ?accountid=39660

Rath,T. (2007). Strenghts finder 2.0. New York Gallup Press.

Rudman, R. (199|). Human resources management in New Zealand (4th ed.). Auckland: Prentice Hall.

Rusten, G., \& Hermelin, B. (2017). Cross-sector collaboration in upper secondary school vocational education: experiences from two industrial towns in Sweden and Norway. Journal of Education and Work. 30(8), 8I 3-826.

Staron, M., Jasinki, M., \& Weatherley, R. (2006). Life based learning: A strengths based approach for capability development in vocation and technical education. from Department of Education, science and training and TAFE NSW http:// lifewidedevelopmentsymposium.pbworks.com/f/Maret\%20Staron\%20FINAL\%20PAPER.pdf

Stone, R. J. (20।3). Human resource management (4th ed.). Milton, Qld: John Wiley \& Sons.

Tener, R. K. (1996). Industry-University partnerships for construction engineering , I 22(4), I 56. https://doi.org/ | 0. I 06 |/(ASCE) I 052 3928(1996) I 22:4(I 56). Education. Journal of Professional Issues in Engineering Education \& Practice. I 22(4), I 56 - 162.

Vega, G. (2009). The undergraduate case research study model. Journal of Management Education. 34(4), 574-604.

Vidal-Salazar, M., Ferrón-Vílchez, V., \& Cordón-Pozo. (2012). Coaching: An effective practice for business competitiveness. Competitiveness Review. 22(5), 423-433.

Waterhouse, P., \& Virgona, C. (2008). Working from strengths:Venturing towards strength-based adult education. National Centre for Vocational Education Research. Retrieved from http://www.ncver.edu.au/research/proj/nl05005.pdf 